\title{
Forest ecosystem changes from annual methane source to sink depending on late summer water balance
}

\section{Citation}

Shoemaker, Julie K., Trevor F. Keenan, David Y. Hollinger, and Andrew D. Richardson. 2014. "Forest Ecosystem Changes from Annual Methane Source to Sink Depending on Late Summer Water Balance." Geophysical Research Letters 41, no. 2: 673-679.

\section{Published Version}

doi:10.1002/2013GL058691

\section{Permanent link}

http://nrs.harvard.edu/urn-3:HUL.InstRepos:12876661

\section{Terms of Use}

This article was downloaded from Harvard University's DASH repository, and is made available under the terms and conditions applicable to Open Access Policy Articles, as set forth at http:// nrs.harvard.edu/urn-3:HUL.InstRepos:dash.current.terms-of-use\#OAP

\section{Share Your Story}

The Harvard community has made this article openly available.

Please share how this access benefits you. Submit a story.

\section{Accessibility}




\section{Forest ecosystem changes from annual methane source to sink depending on late} summer water balance

3 Julie K. Shoemaker ${ }^{1 *}$, Trevor F. Keenan ${ }^{2}$, David Y. Hollinger ${ }^{3}$, Andrew D. Richardson ${ }^{1}$

$4{ }^{1}$ Department of Organismic and Evolutionary Biology. Harvard University. Cambridge, Massachusetts, 02138, USA.

${ }^{2}$ Macquarie University. Department of Biological Sciences. North Ryde, Sydney, Australia, 2109.

$8{ }^{3}$ USDA Forest Service. Northern Research Station. Durham, New Hampshire, 03824, USA.

$10 *$ Corresponding author: Herbarium 422. 15 Divinity Avenue. Cambridge, Massachusetts, 02138, USA (jshoemak@,fas.harvard.edu).

12

13 Key Points

14 Summer precipitation may moderate a methane source-sink transition at this site

15 Ecosystem-scale photosynthesis correlates with methane fluxes over short and long 16 timescales

17 Multiyear flux datasets are needed to build predictive understanding 


\section{Abstract}

20 Forests dominate the global carbon cycle, but their role in methane $\left(\mathrm{CH}_{4}\right)$

21 biogeochemistry remains uncertain. We analyzed whole-ecosystem $\mathrm{CH}_{4}$ fluxes from two

22 years, obtained over a lowland evergreen forest in Maine, USA. Gross primary

23 productivity (GPP) provided the strongest correlation with the $\mathrm{CH}_{4}$ flux in both years,

24 with an additional significant effect of soil moisture in the second, drier, year. This forest

25 was a neutral to net source of $\mathrm{CH}_{4}$ in 2011 and a small net sink in 2012. Inter-annual

26 variability in the summer hydrologic cycle apparently shifts the ecosystem from being a

27 net source to a sink for $\mathrm{CH}_{4}$. The small magnitude of the $\mathrm{CH}_{4}$ fluxes and observed control

28 or $\mathrm{CH}_{4}$ fluxes by forest productivity and summer precipitation provide novel insight into

29 the $\mathrm{CH}_{4}$ cycle in this globally important forest ecosystem.

\section{Introduction}

31 Global forests remove $\mathrm{CO}_{2}$ from the atmosphere at a rate of $\sim 2.4 \mathrm{Pg} \mathrm{C}$ per year $[\mathrm{Pan}$ et

32 al., 2011]. The role of forests in methane $\left(\mathrm{CH}_{4}\right)$ cycling, however, has not been well

33 constrained, in part because of difficulties in assessing $\mathrm{CH}_{4}$ fluxes at the landscape scale.

34 Most of what is known about forest $\mathrm{CH}_{4}$ fluxes is derived from chamber measurements at

35 the level of the soil surface, which show that many forest soils are net consumers of

36 atmospheric $\mathrm{CH}_{4}$ [Megonigal and Guenther, 2008]. Globally, $\mathrm{CH}_{4}$-consuming bacteria in

37 terrestrial soils are believed to account for approximately $5 \%$ of total $\mathrm{CH}_{4}$ oxidation, the

38 second largest sink of atmospheric $\mathrm{CH}_{4}$ while anaerobic (saturated) soils are strong

39 sources of $\mathrm{CH}_{4}$ [Forster et al., 2007]. The division between what constitutes a $\mathrm{CH}_{4}$

40 producing vs consuming soil is murky with upland soils demonstrated to emit $\mathrm{CH}_{4}$ under 
41 certain circumstances [Savage et al., 1997; Whalen et al., 1991; Yavitt et al., 1995; Yavitt

42 et al., 1990] and localized (often discrete) soil flux measurements are difficult to scale up

43 due to their high spatial and temporal variability.

44 Forests with high water tables and organic-rich soils, such as many boreal forests,

45 provide an especially complex picture with dry and wet soil conditions intermixed due to

46 small-scale topographic variability. Such forests have the most potential to produce and

47 emit significant quantities of $\mathrm{CH}_{4}$. In addition, direct interaction of trees with forest $\mathrm{CH}_{4}$

48 emissions have also been posited, either aerobically [Keppler et al., 2006], through

49 internal anaerobic rot [Covey et al., 2012], or with the trees acting as conduits for soil-

50 produced $\mathrm{CH}_{4}$ dissolved in the transpiration stream [Nisbet et al., 2009; Pangala et al.,

51 2013]. Determining what controls the magnitude and seasonality of forest $\mathrm{CH}_{4}$ fluxes

52 above the canopy will define the roles of forest soils and trees in the global $\mathrm{CH}_{4}$ cycle.

53 Recent improvements in fast-response $\mathrm{CH}_{4}$ analyzers have made it possible to measure

54 ecosystem-scale $\mathrm{CH}_{4}$ fluxes by eddy covariance [Peltola, 2011; Smeets et al., 2009;

55 Wang et al., 2013]. Here we present and analyze the first multi-year eddy covariance time

56 series of $\mathrm{CH}_{4}$ fluxes from a forested ecosystem. The results show that the site was a

57 neutral to small net source of $\mathrm{CH}_{4}$ during 2011 but a net sink during 2012. Importantly,

58 no strong $\mathrm{CH}_{4}$ sources, either from the soils or trees, are indicated by this study. The

59 strongest correlate for the 4-day averaged $\mathrm{CH}_{4}$ flux dynamics was GPP during both years,

60 with soil moisture accounting for significant variance during dry periods. Our results

61 suggest that multi-year studies will be critical to developing model structures capable of

62 reproducing net fluxes and predicting changes in future $\mathrm{CH}_{4}$ fluxes from forested

63 ecosystems. 


\section{Methods}

\section{Site Description}

66 Research was conducted at the Howland Forest AmeriFlux site located about 35 miles

67 north of Bangor, Maine, USA $\left(45^{\circ} 15^{\prime} \mathrm{N}, 68^{\circ} 44^{\prime} \mathrm{W}, 60 \mathrm{~m}\right.$ asl) on forestland owned by

68 the Northeast Wilderness Trust. Howland Forest is a boreal-temperate transition forest,

69 with stands dominated by red spruce (Picea rubens Sarg.) and eastern hemlock (Tsuga

70 canadensis (L.) Carr.) with lesser quantities of other conifers and hardwoods. The soils

71 have never been cultivated and the upland soils are classified as Skerry fine sandy loam,

72 Aquic Haplorthods. Peats have formed in the poorly drained positions dominated by

73 sphagnum. Fernandez et al. [1993], and Hollinger et al. [1999; 2004] have previously

74 described the climate, soils, and vegetation at the site.

\section{$75 \quad$ Flux measurements}

76 Fluxes were measured at a height of $29 \mathrm{~m}$ with systems consisting of a model SAT-

77 211/3K 3-axis sonic anemometer (Applied Technologies Inc., Longmont, CO, USA) and

78 a fast-response $\mathrm{CH}_{4} / \mathrm{CO}_{2} / \mathrm{H}_{2} \mathrm{O}$ cavity ring down spectrometer (model G1301-f in 2011

79 and G2311-f in 2012; Picarro Inc., Santa Clara, CA) with data recorded at $5 \mathrm{~Hz}$. The $\mathrm{CO}_{2}$

80 flux measurements were also independently quantified with a co-deployed fast response

$81 \mathrm{CO}_{2} / \mathrm{H}_{2} \mathrm{O}$ infrared gas analyzer (model Li-7200, Li-Cor Inc., Lincoln, NE, USA). In 2011,

$82 \mathrm{H}_{2} \mathrm{O}$ concentrations measured with the Li-7200 were used for density correction of $\mathrm{CO}_{2}$

83 and $\mathrm{CH}_{4}$ fluxes measured with the G1301-f because that instrument could not output all

84 three concentrations simultaneously. Fluxes were calculated and filtered according to

85 Hollinger et al. [1999; 2004]. In 2012, fluxes were calculated via the same equations and

86 assumptions (600 s time constant running mean filter, double rotation, etc.) using 
87 commercially available software (EddyPro version 4, Li-Cor Inc., Lincoln, NE, USA). In

88 both years, the $\mathrm{CO}_{2}$ fluxes were nearly identical between the Picarro and Licor analyzers

89 (Fig S1). The sign convention used is that flux to the ecosystem is defined as negative.

90 Further details on the filtering of the flux data are available in the SI.

\section{Environmental Data}

92 Profiles of soil temperature and soil moisture were measured hourly at 5, 10, 20, 50, and

$93100 \mathrm{~cm}$ using Hydra probes (Stevens Water Monitoring Systems Inc., Beaverton, OR,

94 USA) 20 near the base of the tower. Water table depth was measured using a

95 barometrically compensated pressure transducer (model WL400, Global Water, Gold

96 River, CA, USA) in a shallow well. Solar radiation (photosynthetic photon flux density,

97 PPFD), air temperature, and precipitation were measured from the top of the flux tower

98 as described previously [Hollinger et al., 2004]. We note that the measurement scale for

99 the soil data differs from that of the flux data.

100 Statistical Analyses

101 The half-hourly $\mathrm{CH}_{4}$ flux data were low-pass filtered to give a set of mean fluxes, each

102 representing a 4-day window. This was combined with Monte-Carlo resampling in order

103 to obtain an estimate of the uncertainty on these mean fluxes. Details are available in the 104 SI.

105 We used an Artificial Neural Network (ANN) to characterize the climatic sensitivity of

106 ecosystem-atmosphere $\mathrm{CH}_{4}$ exchange and to estimate annual $\mathrm{CH}_{4}$ budgets. This

107 methodology choice is supported by a recent study showing the effectiveness of ANNs

108 for gap-filling $\mathrm{CH}_{4}$ fluxes [Dengel et al., 2013]. An ANN is an inductive approach based 
109 on statistical multivariate modeling [Bishop, 1995; Rojas, 1996] by which one can map

110 drivers directly onto observations [Moffat et al., 2010]. We used a feed-forward ANN

111 with a sigmoid activation function trained with a back propagation algorithm. An

112 ensemble of 100 ANNs was trained both on the hourly and running mean aggregated

113 eddy-covariance $\mathrm{CH}_{4}$ fluxes independently. See SI for description of our 3-stage training

114 process.

\section{Results}

116 Many variables including GPP, air temperature, $\mathrm{PPFD}, \mathrm{CO}_{2}$ flux, and soil moisture and

117 soil temperature at 10 and $20 \mathrm{~cm}$ were significantly correlated (Kendall rank correlation,

$118 \mathrm{p}<<0.01$ ) with the $\mathrm{CH}_{4}$ flux signal in both years, but any combination of these variables

119 explains only a small fraction of the variation in the $\mathrm{CH}_{4}$ fluxes (multiple $\mathrm{r}^{2}<0.05$ ) at the

12030 minute time step. The neural network approach was able to explain a maximum of 8-

$12110 \%$ of the total variability in the data for each year (Fig S3) using a combination of

122 environmental drivers (GPP, air temperature, wind direction, wind speed, relative

123 humidity, soil moisture, soil temperature, and water table depth). The individual driver

124 with the highest explanatory power in the ANN was air temperature in 2011 and GPP in

125 2012. These low correlations emerge because of the large random errors (noise) in the

126 measurement, which argues for the use of statistical approaches for time averaging of the

127 data to reduce uncertainties and permit elucidation of the trends.

128 Averaging the fluxes by time of day, we observed more $\mathrm{CH}_{4}$ efflux during the daytime

129 and more $\mathrm{CH}_{4}$ consumption at night. This pattern was only present during summer

130 months (Fig S4). We used a wavelet coherence analysis as an alternate approach for

131 examining the significance of this diurnal structure. Using this analysis we found 
132 coherent periodic behavior in both the $\mathrm{CH}_{4}$ and GPP signals at the 18-28 hour time scale

133 over the summer and early fall seasons, although the time periods when this relationship

134 was significant were intermittent. The coherence between the $\mathrm{CH}_{4}$ flux and GPP signals

135 was stronger than between $\mathrm{CH}_{4}$ flux and air temperature. Due in part to the intermittent

136 nature of the coherence, it was not possible to determine whether $\mathrm{CH}_{4}$ flux lagged GPP,

137 which could potentially indicate a causal relationship.

138 The use of 4-day mean fluxes elucidated the seasonal pattern in the $\mathrm{CH}_{4}$ flux data. $\mathrm{CH}_{4}$

139 fluxes were mostly positive during the summer months, trending negative in the late

140 summer or fall, then remaining consistently negative through the winter months (Fig 1).

141 By comparison, the $\mathrm{CO}_{2}$ fluxes (here processed as GPP) showed the opposite pattern with

142 the highest rates of $\mathrm{CO}_{2}$ uptake during the midsummer, followed by decreasing uptake

143 through the fall into the winter.

144 The spring and summer precipitation patterns differed between 2011 and 2012. While the

145 total annual precipitation measured at the tower was lower in $2011(870 \mathrm{~mm})$ than in

$1462012(940 \mathrm{~mm})$, the precipitation during July and August was much greater during 2011

147 than 2012 (224 vs $76 \mathrm{~mm}$ ). This precipitation change led to a large difference in

148 summer/fall soil moisture between the years (Fig 1). Historical precipitation data

149 (http://www.ncdc.noaa.gov/cdo-web/) from Millinocket station (located $\sim 50 \mathrm{~km}$ north of

150 Howland forest) for July and August for 1970-2010 gives a mean $( \pm 1$ sd) precipitation of

$151200 \pm 73 \mathrm{~mm}$ for those months combined. In 2011 Millinocket recorded July-August

152 precipitation of $282 \mathrm{~mm}$ during 2011, compared with $127 \mathrm{~mm}$ for 2012, indicating that

1532011 was wetter than the $40-y r$ average whereas 2012 was drier than average. 
154 Using a wide selection of variables (air temperature, soil temperature, soil moisture, wind

155 direction, water table depth, relative humidity, and wind speed) the ANN produced a

156 model explaining nearly $65 \%$ and $90 \%$ of the variability in the 4-day $\mathrm{CH}_{4}$ fluxes during

1572011 and 2012. However, to reduce the redundancy due to correlations between many of

158 these drivers, we forced the ANN to use GPP and then tested for the additional

159 explanatory power (if any) attained by each remaining driver (Fig 2, S5). GPP was

160 chosen because it was the individual variable with the highest explanatory power in both

161 years. The importance of each driver using this reduced approach is shown in Fig 2. We

162 observe that, in 2011 and 2012 respectively, variation in GPP accounted for $60 \%$ and

$16350 \%$ of the variability in the 4-day $\mathrm{CH}_{4}$ fluxes. Including soil moisture increases the

164 explanatory power of the model by $>10 \%$ during 2012 (the drier year) but has negligible

165 influence in 2011 (the wetter year). Therefore, a model using only GPP and 10-cm soil

166 moisture was able to explain $\sim 60$ and $70 \%$ of the variability in $4-\mathrm{d}$ mean $\mathrm{CH}_{4}$ fluxes for

1672011 and 2012. All other drivers provide negligible improvement to the model fit. This

168 order of importance of drivers was supported by separate linear regression analysis

169 (Table S1).

170 Despite the fact that the principal environmental drivers were the same in both years,

171 models derived from the 2011 fluxes did a poor job predicting $\mathrm{CH}_{4}$ fluxes in 2012, and

172 vice versa (Fig. S6). We also trained the model on the 4-day means from both years

173 together and while the ANN produced a model that explained $40 \%$ of the variability in all

174 the data this represented a substantial decrease in goodness-of-fit compared to modeling

175 each year individually. 
176 We estimated the annual $\mathrm{CH}_{4}$ budgets for 2011 and 2012 for Howland forest in two

177 ways; using either the ANN or a linear model combined with Monte Carlo resampling.

178 Using the linear modeling approach (Fig S7) we estimate net efflux (mean \pm 1 sd) of $7 \pm$

$1794.6 \mathrm{mmol} \mathrm{m}^{-2} \mathrm{yr}^{-1}$ for 2011 and consumption $-18 \pm 2.7 \mathrm{mmol} \mathrm{m}^{-2} \mathrm{yr}^{-1}$ for 2012. Using the

180 ANN, annual fluxes were $6 \pm 11 \mathrm{mmol} \mathrm{m}^{-2} \mathrm{yr}^{-1}$ for 2011 , and $-9 \pm 3.7 \mathrm{mmol} \mathrm{m}^{-2} \mathrm{yr}^{-1}$ for

1812012 (Fig 2). Larger uncertainties were contributed by the first few months of the year

182 due to the absence of measurements to constrain the model during these periods. This

183 increase in variance was particularly large in the ANN because of its inherently nonlinear

184 structure. Both approaches indicated that the annual $\mathrm{CH}_{4}$ flux in 2011 was small but

185 likely positive while the forest was a net consumer of $\mathrm{CH}_{4}$ in 2012.

\section{Discussion}

187 The lowland evergreen forest studied was an intermittent source of $\mathrm{CH}_{4}$ to the

188 atmosphere, showing efflux from July through October during 2011, and from June

189 through July 2012 while recording net uptake for the remainder of each year (Fig 1).

190 Using an artificial neural network (ANN), we found that a combination of GPP and 10-

$191 \mathrm{~cm}$ soil moisture was able to explain 60 and $70 \%$ of the variability in 4-d mean $\mathrm{CH}_{4}$

192 emissions for 2011 and 2012 individually (Fig 2), while use of all the drivers resulted in a

193 model explaining nearly $90 \%$ of the variability during 2012 (the maximum explainable

194 variance in 2011 is just above $60 \%$ ). Additionally, a diurnal cycle was present in the $\mathrm{CH}_{4}$

195 flux signal during the summer and fall that was consistent with that observed in GPP. The

196 ANN, supported by linear modeling, consistently found GPP to be a stronger correlate of

197 the 4-day mean $\mathrm{CH}_{4}$ fluxes than air temperature. 
198 Gross primary production is highly correlated with a wide variety of other environmental

199 parameters, such as air temperature, PPFD, and soil temperature, and it could be argued

200 that GPP is driving $\mathrm{CH}_{4}$ emissions only indirectly through cross-correlations. The a priori

201 assumption would be that $\mathrm{CH}_{4}$ fluxes are controlled by soil moisture [Adamsen and King,

202 1993; Castro et al., 1994; Castro et al., 1995] due to the dependence of both $\mathrm{CH}_{4}$

203 oxidation and $\mathrm{CH}_{4}$ production on soil diffusivity (through $\mathrm{O}_{2}$ availability) with

204 temperature being a secondary controlling variable [Castro et al., 1995] due to the

205 positive influence of temperatures on reaction rates (positive Q10 values). However, both

206 the neural network and linear modeling approaches found GPP to be the stronger

207 predictor of $\mathrm{CH}_{4}$ emissions when treating each year individually, or together, with soil

208 moisture only important during 2012.

209 There are several mechanistic reasons why changes in GPP may lead to changes in $\mathrm{CH}_{4}$

210 emissions. First, $\mathrm{CH}_{4}$ production rates have been linked to photosynthesis through root

211 exudation in some wetlands [King and Reeburgh, 2002]. Carbon isotope studies have

212 shown that most $\mathrm{CH}_{4}$ released from wetlands is derived from "new carbon" rather than

213 from dissolved soil organic matter [Chanton et al., 1995]. In a rice paddy, wavelet

214 coherence analysis found the diurnal cycle in $\mathrm{CH}_{4}$ emissions to be driven by GPP [Hatala

215 et al., 2012]. However, trees may also be influencing the seasonal and diurnal cycle if

216 dissolved $\mathrm{CH}_{4}$ is emitted through transpired soil water [Nisbet et al., 2009], such that

217 GPP could be more proxy than mechanism. It is more difficult to directly connect $\mathrm{CH}_{4}$

218 oxidation and GPP, although microbial priming could link these processes. In this case,

219 carbon leakage from the roots of trees and other plants increases total microbial activity;

220 because many $\mathrm{CH}_{4}$ oxidizing bacteria are capable of consuming a wide variety of 
221 methylated substrates their population dynamics could respond to overall soil carbon

222 degradation rates, leading to higher rates of $\mathrm{CH}_{4}$ oxidation linked to increased soil

223 respiration activity. We interpret these results as indicating a significant role for GPP in

224 influencing $\mathrm{CH}_{4}$ flux, both in its high frequency and low frequency variability although

225 we acknowledge that the mechanism is not yet clear.

226 The role of soil moisture in forest $\mathrm{CH}_{4}$ flux may involve a threshold: once volumetric soil

227 moisture exceeds some level (here $\sim 0.1 \mathrm{WFV}$ ), there are sufficient anoxic pore spaces to

228 support $\mathrm{CH}_{4}$ production near the surface and correlations become weak, while below this

229 threshold, soil moisture is an important factor controlling the balance between $\mathrm{CH}_{4}$

230 production and $\mathrm{CH}_{4}$ oxidation. It is also possible that the lower correlations are a result of

231 spatial variability in soil moisture over the tower footprint related to the small-scale

232 topography that was not captured by this study. However, the trends of drying and

233 wetting, also observed in the precipitation data, would be expected to be felt to some

234 degree throughout the landscape. Overall, we found soil moisture had a smaller overall

235 influence than GPP but remains important under drier conditions.

236 Despite the high correlations of a model using GPP and soil moisture to the data in each

237 year, the explanatory power of these models diminished almost to zero when applied to

238 data on which the model was not trained (Fig S6). Similar challenges have been observed

239 with modeling $\mathrm{CH}_{4}$ fluxes [Mastepanov et al., 2012; Moore et al., 2011; Treat et al.,

240 2007], as well as $\mathrm{CO}_{2}$ fluxes [Richardson et al., 2007] from a variety of environments.

$241 \mathrm{Net}^{\mathrm{CH}_{4}}$ emission is the result of two processes acting in opposition $-\mathrm{CH}_{4}$ production

242 and $\mathrm{CH}_{4}$ oxidation, and it appears that a correlative model based on emissions may lack

243 the appropriate structure needed to extrapolate fluxes over longer timescales, despite 
244 success over shorter timescales. Achieving an appropriate model structure and

245 complexity is necessary for improving the $\mathrm{CH}_{4}$ components of larger earth-system

246 models and predicting natural $\mathrm{CH}_{4}$ emissions from forests under changing environmental

247 conditions. Multiple years of flux measurements under a range of conditions will be

248 needed to accurately characterize the climatic and physiological dependence of forest

$249 \mathrm{CH}_{4}$ fluxes. Experimental methods combining ecosystem-scale flux measurements, soil

250 chamber flux measurements, and soil-gas profiles may also provide needed insight into

251 the mechanistic controls driving both the sign and magnitude of $\mathrm{CH}_{4}$ flux.

252 In the context of the overall climate impact of greenhouse gas fluxes at this site, the $\mathrm{CH}_{4}$

253 fluxes are small contributors (see $\mathrm{SI}$ ) relative to the total $\mathrm{CO}_{2}$ uptake. This contrasts with

254 other ecosystems, such as boreal wetlands where the climate impact of $\mathrm{CH}_{4}$ fluxes can be

255 larger than the climate benefit of their $\mathrm{CO}_{2}$ uptake [Whiting and Chanton, 2001].

\section{Conclusions}

257 We provide the first multi-year set of $\mathrm{CH}_{4}$ fluxes measured by eddy-covariance over a

258 forested ecosystem. Multi-year data sets of $\mathrm{CH}_{4}$ fluxes capturing a wide variety of

259 environmental conditions are critical to developing model structures that are capable of

260 adequately predicting future $\mathrm{CH}_{4}$ fluxes. GPP provided the strongest correlation with the

261 calculated 4-day mean $\mathrm{CH}_{4}$ fluxes during each year. Including soil moisture as a driver

262 for $\mathrm{CH}_{4}$ production improved the fit of the model only during 2012, which had a drier

263 than average summer. Despite the potential for $\mathrm{CH}_{4}$ efflux from this temporate-boreal

264 transition site, our observations suggest that neither the soils nor trees are large sources of

$265 \mathrm{CH}_{4}$ from the forest to the atmosphere. This study finds evidence for a link between GPP 
266 and $\mathrm{CH}_{4}$ flux, and a small sink/source transition controlled by summer hydrologic

267 conditions.

\section{Acknowledgements}

269 Research at Howland Forest is supported by the Office of Science (BER), US Department

270 of Energy through interagency agreement number DE-AI02-11ER65199. We also

271 recognize contributions from Robert Evans, Holly Hughes, Kathleen Savage, John Lee

272 and Eric Davidson.

\section{References}

274 Adamsen, A. P. S., and G. M. King (1993), Methane consumption in temperate and

275 subarctic forest soils: Rates, vertical zonation, and responses to water and nitrogen,

276 Applied and Environmental Microbiology, 59(2), 485-490.

277 Bishop, C. M. (1995), Neural Networks for Pattern Recognition, Oxford University Press,

278 Oxford, United Kingdom.

279 Castro, M. S., J. M. Melillo, P. A. Steudler, and J. W. Chapman (1994), Soil moisture as

280 a predictor of methane uptake by temperate forest soils, Canadian Journal of Forest

281 Research, 24(9), 1805-1810.

282 Castro, M. S., P. A. Steudler, J. M. Melillo, J. D. Aber, and R. D. Bowden (1995),

283 Factors controlling atmospheric methane consumption by temperate forest soils, Global

284 Biogeochemical Cycles, 9(1), 1-10.

285 Chanton, J. P., J. E. Bauer, P. A. Glaser, D. I. Siegel, C. A. Kelley, S. C. Tyler, E. H.

286 Romanowicz, and A. Lazrus (1995), Radiocarbon evidence for the substrates supporting

287 methane formation within Northern Minnesota peatlands, Geochim. Cosmochim. Acta, 288 59(17), 3663-3668. 
289 Covey, K. R., S. A. Wood, R. J. Warren, X. Lee, and M. A. Bradford (2012), Elevated

290 methane concentrations in trees of an upland forest, Geophysical Research Letters,

$29139(15)$, L15705.

292 Dengel, S., D. Zona, T. Sachs, M. Aurela, M. Jammet, F. J. W. Parmentier, W. Oechel, 293 and T. Vesala (2013), Testing the applicability of neural networks as a gap-filling method 294 using CH4 flux data from high latitude wetlands, Biogeosciences Discuss., 10(5), 77272957759.

296 Fernandez, I. J., Y. Son, C. R. Kraske, L. E. Rustad, and M. B. David (1993), Soil carbon 297 dioxide characteristics under different forest types and after harvest, Soil Sci. Soc. Am. J., 298 57(4), 1115-1121.

299 Forster, P., et al. (2007), Changes in Atmospheric Consituents and in Radiative Forcing., 300 in Climate Change 2007: The Physical Science-Basis. Contribution of Working Group 1

301 to the Fourth Assessment Report of the Intergovernmental Panel on Climate Change,

302 edited by S. Solomon, D. Qin, M. Manning, Z. Chen, M. Marquis, K.B. Averyt,

303 M.Tignor and H. L. Miller, Cambridge University Press, Cambridge, United Kingdom

304 and New York, NY, USA.

305 Hatala, J. A., M. Detto, and D. D. Baldocchi (2012), Gross ecosystem photosynthesis

306 causes a diurnal pattern in methane emission from rice, Geophysical Research Letters, 307 39(6), L06409.

308 Hollinger, D. Y., S. M. Goltz, E. A. Davidson, J. T. Lee, K. Tu, and H. T. Valentine

309 (1999), Seasonal patterns and environmental control of carbon dioxide and water vapour

310 exchange in an ecotonal boreal forest, Global Change Biology, 5(8), 891-902. 
311 Hollinger, D. Y., et al. (2004), Spatial and temporal variability in forest-atmosphere CO2

312 exchange, Global Change Biology, 10(10), 1689-1706.

313 Keppler, F., J. T. G. Hamilton, M. Brab, and T. Rockman (2006), Methane emissions

314 from terrestrial plants under aerobic conditions, Nature, 439(12), 187-191.

315 King, J. Y., and W. S. Reeburgh (2002), A pulse-labeling experiment to determine the

316 contribution of recent plant photosynthates to net methane emission in arctic wet sedge

317 tundra, Soil Biol. Biochem., 34(2), 173-180.

318 Mastepanov, M., C. Sigsgaard, T. Tagesson, L. Str $\sqrt{\partial m}$, M. P. Tamstorf, M. Lund, and T.

319 R. Christensen (2012), Revisiting factors controlling methane emissions from high-arctic

320 tundra, Biogeosciences Discussions, 9(11), 15853-15900.

321 Megonigal, J. P., and A. B. Guenther (2008), Methane emissions from upland forest soils 322 and vegetation, Tree Physiology, 28(4), 491-498.

323 Moffat, A. M., C. Beckstein, G. Churkina, M. Mund, and M. Heimann (2010),

324 Characterization of ecosystem responses to climatic controls using artificial neural

325 networks, Global Change Biology, 16(10), 2737-2749.

326 Moore, T., A. Young, J. Bubier, E. Humphreys, P. Lafleur, and N. Roulet (2011), A

327 Multi-Year Record of Methane Flux at the Mer Bleue Bog, Southern Canada, Ecosystems, $328 \quad 14(4), 646-657$.

329 Nisbet, R. E. R., et al. (2009), Emission of methane from plants, Proceedings of the

330 Royal Society B: Biological Sciences, 276(1660), 1347-1354.

331 Pan, Y., et al. (2011), A large and persistent carbon sink in the world's forests, Science, $332333(6045), 988-993$. 
333 Pangala, S. R., S. Moore, E. R. C. Hornibrook, and V. Gauci (2013), Trees are major

334 conduits for methane egress from tropical forested wetlands, New Phytologist, 197(2),

$335 \quad 524-531$.

336 Peltola, O. (2011), Field intercomparison of four methane gas analysers suitable for eddy

337 covariance flux measurements.

338 Richardson, A. D., D. Y. Hollinger, J. D. Aber, S. V. Ollinger, and B. H. Braswell (2007),

339 Environmental variation is directly responsible for short- but not long-term variation in

340 forest-atmosphere carbon exchange, Global Change Biology, 13(4), 788-803.

341 Rojas, R. (1996), Neural Networks: A Systematic Introduction, Springer-Verlag, Berlin,

342 Germany.

343 Savage, K., T. R. Moore, and P. M. Crill (1997), Methane and carbon dioxide exchanges

344 between the atmosphere and northern boreal forest soils, J. Geophys. Res., 102(D24),

$345 \quad 29279-29288$.

346 Smeets, C., R. Holzinger, I. Vigano, A. Goldstein, and T. R Vackmann (2009), Eddy

347 covariance methane measurements at a Ponderosa pine plantation in California,

348 Atmospheric Chemistry and Physics, 9(21), 8365-8375.

349 Treat, C. C., J. L. Bubier, R. K. Varner, and P. M. Crill (2007), Timescale dependence of

350 environmental and plant-mediated controls on CH4 flux in a temperate fen, J. Geophys.

351 Res.-Biogeosci., $112(\mathrm{G} 1), \mathrm{G} 01014$.

352 Wang, J. M., J. G. Murphy, J. A. Geddes, C. L. Winsborough, N. Basiliko, and S. C.

353 Thomas (2013), Methane fluxes measured by eddy covariance and static chamber

354 techniques at a temperate forest in central Ontario, Canada, Biogeosciences, 10(6), 4371-

3554382. 
356 Whalen, S. C., W. S. Reeburgh, and K. S. Kizer (1991), Methane consumption and

357 emission by Taiga, Global Biogeochemical Cycles, 5(3), 261-273.

358 Whiting, G. J., and J. P. Chanton (2001), Greenhouse carbon balance of wetlands:

359 methane emission versus carbon sequestration, Tellus B, 53(5), 521-528.

360 Yavitt, J. B., T. J. Fahey, and J. A. Simmons (1995), Methane and carbon dioxide

361 dynamics in a northern hardwood ecosystem, Soil Sci. Soc. Am. J., 59(3), 796-804.

362 Yavitt, J. B., D. M. Downey, G. E. Lang, and A. J. Sexston (1990), Methane consumption

363 in two temperate forest soils, Biogeochemistry, 9(1), 39-52.

\section{Figure Legends}

365 Figure 1: The 4-day running mean $\mathrm{CH}_{4}$ fluxes (open circles) with 4-day mean GPP (grey

366 stars) and volumetric soil moisture at $10 \mathrm{~cm}$ (black squares). Data from 2011 is shown in

367 the top panel against data from 2012 in the lower panel. The dotted black line highlights

368 the line of 0 flux, above which the forest is a net source of $\mathrm{CH}_{4}$ to the atmosphere and

369 below which the forest is a net sink for $\mathrm{CH}_{4}$.

370 Figure 2: Results from the ANN for both years, with the top panels indicating the

371 importance of various environmental drivers contributing to the model. Each

372 environmental driver is shown separately with the black portion of the column indicating

373 the additional predictive power this driver gives the model when combined with GPP (the

374 grey portion of the column). The horizontal dotted lines indicate the maximum attainable

375 predictive capacity if all drivers are used simultaneously. The bottom panels show the

376 ANN modeled fluxes for the entire year (black lines) \pm 1 sd (vertical bars). 